\title{
Inovações tecnológicas como instrumento de educação para a higienização do açaí em uma comunidade ribeirinha da Amazônia: um relato de experiência
}

\author{
Technological innovations as an instrument of education for the hygienization of açaí in a \\ ribeirinha community of the Amazon: a report of experience
}

Innovaciones tecnológicas como instrumento de educación para la higienización del açaí en una comunidad ribeirinha de la Amazonia: un relato de experiencia

\begin{abstract}
lanny Ferreira Raiol ${ }^{1 *}$, Ana Caroline Oliveira Almeida ${ }^{1}$, Alanna Patricia da Cruz Barros ${ }^{1}$, Amanda Rodrigues Figueiredo', Shirley Aviz de Miranda1, Maria Rute de Souza Araújo¹.
\end{abstract}

\section{RESUMO}

Objetivo: Relatar uma ação educativa por meio de tecnologias educacionais sobre medidas profiláticas da Doença de Chagas em uma região ribeirinha no município de Barcarena. Relato de Experiência: Trata-se de uma ação educativa, em uma comunidade ribeirinha de Barcarena-PA. A construção da atividade foi baseada nas etapas do Arco de Maguerez. Em busca da teorização o grupo participou de uma capacitação de manipuladores do fruto do açaí realizado pela vigilância sanitária. Tecnologias utilizadas: Exposição de imagens, reprodução do passo a passo de como higienizar de forma correta o fruto, distribuição de folders e uma dinâmica. Participaram da ação educativa 25 ribeirinhos, a maioria apresenta baixo nível de escolaridade, o que dificulta o entendimento da população para prevenção. Em relação aos conhecimentos sobre como higienizar o fruto do açaí todos demonstraram não realizar o processo de forma adequada, o que pode gerar um grande risco de adquirir a doença. Conclusão: Vale ressaltar a importância de projetos/ações que visem à prevenção da doença através de tecnologias inovadoras. Sendo de suma importância para que o processo de ensino-aprendizagem se consolide.

Palavras-chave: Inovações Tecnológicas, Branqueamento, Educação em saúde.

\begin{abstract}
Objective: to disseminate an educational action on the educational environment on the prophylaxis of Chagas' disease in a riverine region in the municipality of Barcarena. Experience Report: This is an educational action in a riverine community in Barcarena-PA. The construction of the activity was based on the steps of the Arch of Maguerez. In search of theorization the group participated in a training of manipulators of the fruit of açaí carried out by sanitary surveillance. Technologies used: Exhibition of images, reproduction of a step of how to sanitize in a certain way, Distribution of folders and a dynamic. Twenty-five coastal communities participated in the educational action, a series with a low level of schooling, which hampers the understanding of the population for prevention. Regarding procedures on how to protect açaí fruit, all processes have been performed and improved to obtain a higher risk of acquiring a disease. Conclusion: It is worth highlighting the importance of projects / actions that aim to prevent disease through innovative technologies. Important importance for the teaching-learning process to be consolidated.
\end{abstract}

Key words: Technological Innovations, Bleaching, Health education.

${ }^{1}$ Centro Universitário Metropolitano da Amazônia (UNIFAMAZ), Belém-Pará. *E-mail: raiolianny@hotmail.com

SUBMETIDO EM: 5/2019

ACEITO EM: 6/2019

PUBLICADO EM: 7/2019

REAS/EJCH | Vol. Sup.27 | e920 | DOI: https://doi.org/10.25248/reas.e920.2019 Página 1 de 6 


\section{RESUMEN}

Objetivo: divulgar una acción educativa sobre el medio educativo sobre la profilaxis de la Enfermedad de Chagas en una región ribereña en el municipio de Barcarena. Relato de Experiencia: Se trata de una acción educativa, en una comunidad ribereña de Barcarena-PA. La construcción de la actividad se basó en las etapas del Arco de Maguerez. En busca de la teorización el grupo participó de una capacitación de manipuladores del fruto del açaí realizado por la vigilancia sanitaria. Tecnologías utilizadas: Exposición de imágenes, reproducción de un paso de cómo higienizar de cierta forma, Distribución de carpetas y una dinámica. Participaron de la acción educativa 25 ribereños, una serie con bajo nivel de escolaridad, lo que dificulta el entendimiento de la población para la prevención. En cuanto a los procedimientos sobre cómo proteger el fruto del açaí, todos los procesos fueron realizados y mejorados para obtener un mayor riesgo de adquirir una enfermedad. Conclusión: Vale resaltar la importancia de proyectos / acciones que apunte a la prevención de la enfermedad a través de tecnologías innovadoras. Su importancia para el proceso de enseñanzaaprendizaje se consolida.

Palabras clave: Innovaciones Tecnológicas, Blanqueamiento, Educación en salud.

\section{INTRODUÇÃO}

A doença de Chagas (DC) é uma doença endêmica causada por uma contaminação humana ocasionada pelo protozoário Trypanosoma cruzi. A transmissão ocorre pela forma vetorial, transfusional, transplante, congênita e oral. Atualmente, a via oral é a mais frequente na Amazônia devido à ocorrência de surtos relacionados ao consumo de açaí, em diferentes estados brasileiros, especialmente no Pará (DIAS JCP, et al., 2016).

Os ribeirinhos são considerados como um dos povos tradicionais da floresta, as quais desenvolvem um modo particular de viver e possuem um vasto conhecimento sobre a natureza na qual estão inseridos. As comunidades tradicionais são culturalmente diferenciadas das outras formas de organização, possuem formas próprias de organização social, ocupam e usam o território e recursos naturais para sua "reprodução cultural, social, religiosa, ancestral e econômica", utilizam práticas geradas e transmitidas pela tradição de geração em geração, dentre elas o manejo e consumo do açaí (GRZEBIELUKA D, 2012).

O açaí hoje é considerado um alimento essencial principalmente para a população da região Norte do país. O que indica a necessidade de estratégias de vigilância que estejam relacionadas ao modo de manipulação do fruto (VARGAS A, et al., 2016).

Para estabelecer boas práticas de saúde e higienização, o açaí deve passar por uma série de processos desde a coleta até o preparo para consumo como peneiramento, lavagens, branqueamento, despolpamento, com o objetivo de garantir um produto seguro ao comprador e, consequentemente uma diminuição no número de contaminação ao ser humano (ARAÚJO RS, et al., 2015).

O controle dos vetores, o Triatoma infestans ("barbeiro"), por meio dos inseticidas é importante, mas a maior prevenção ocorre por intermédio de ações impactantes que minimizem as infestações e os decorrências ambientais, mediante processo de melhorias habitacionais e de higiene (OLIVEIRA FLB, et al., 2017).

No período de 2007 a 2014 foram diagnosticados 884 casos agudos e crônicos de DC em 39 municípios do estado do Pará, sendo que, na microrregião de Belém, são notificados, anualmente, cerca de 130 casos novos. Entre esses municípios encontra-se Barcarena, que apresentou o quarto maior número de casos confirmados de DC e a maior prevalência dessa doença no Brasil, com taxa de 89,38 casos por 100 mil habitantes. (JÚNIOR ASS, et al., 2017).

Segundo o DataSus (2017) foram notificados 247 casos de doença de chagas aguda no estado do Pará transmitido por via oral, destacando-se os municípios com os maiores números de casos: Ananindeua (75), Breves (34), Abaetetuba (31), Belém (25) e Barcarena (12). 
É essencial que os profissionais de saúde entendam que a ausência de registros referentes a exames laboratoriais específicos para DC e o preenchimento inadequado das fichas de notificação e investigação comprometem o fechamento dos casos (SANTOS VRC, et al., 2018).

A educação em saúde como método educativo requer a evolução de um pensar crítico e reflexivo, consentindo desvelar a realidade e propor ações transformadoras que levem o indivíduo à sua independência e emancipação como sujeito histórico e social, capaz de propor e opinar nas decisões de saúde para cuidar de si, de sua família e de seu grupo (FALKENBERG MB, et al., 2014).

As tecnologias educacionais tem o propósito de auxiliar no conhecimento e interferir nas práticas educativas da comunidade. A expressão tecnologia jamais deve ser compreendida somente como produto, mas também como produto e estratégia social criado com base nas experiências entre sujeitos que são alcançados e compartilhados; podem ser instrumentais ou relacionais que podem ser usufruídas a fim de simplificar e auxiliar na execução de técnicas educativas e educação em saúde (SILVEIRA RSO, et al., 2016).

Consideram-se as tecnologias educativas como metodologia inovadora que possibilita dar ênfase ao processo de ensino, aprendizagem e avaliação, ao proporcionar técnicas e instrumentos integrados ao desenvolvimento do sistema educacional, proporcionando adquirir uma mentalidade crítica, colocando-os como agente proativa e estimulando-os a buscar respostas para problemas reais e complexos (SILVEIRA RSO, et al., 2016).

Dessa forma, o objetivo geral desse trabalho é relatar uma ação educativa por meio de tecnologias educacionais sobre medidas profiláticas da Doença de Chagas em uma região ribeirinha no município de Barcarena.

\section{RELATO DE EXPERIÊNCIA}

Trata-se de uma ação educativa tipo relato de experiência, sobre a higienização do fruto do açaí para o controle da doença de chagas em uma comunidade ribeirinha no município de Barcarena-Pará.

A ação educativa foi desenvolvida em uma ilha de uma comunidade ribeirinha do Rio Piramanha Alto II no Centro Comunitário São José. Que faz parte do território da Estratégia Saúde da Família (ESF), situada na Ilha das Onças, no município Barcarena - Pará. Está distante de Belém, capital do Estado, uma hora através de embarcações. Ocorreu no horário de 08:00 às 11:30 horas do dia 10 de abril de 2019. O público alvo foi à comunidade ribeirinha atendida pela ESF.

A equipe é formada por uma enfermeira, um médico, um técnico de enfermagem, e sete Agentes Comunitários de Saúde (ACS). A ESF atende um total de 2.600 pessoas cadastradas no programa. A assistência prestada às famílias é realizada através de consultas médicas, consultas de enfermagem, consultas de nutrição.

A construção da atividade foi baseada na metodologia da problematização e das etapas do Arco de Maguerez, as quais: a primeira etapa foi uma observação da realidade, por meio de uma visita técnica prévia na Unidade de Saúde da Família Furo do Nazário, que permitiu conhecer a localidade e fazer o levantamento de uma problemática. A segunda etapa foi identificação dos pontos-chaves sobre as possíveis vulnerabilidades relacionadas à higienização do fruto. Na terceira etapa aconteceu a teorização, onde ocorre a investigação através da imersão teórica sobre a temática. A quarta etapa consistiu na busca de inovações tecnológicas referentes à problemática, por meio de metodologias ativas que visam minimizar a situação identificada e a quinta etapa se constituiu na execução em si da ação educativa.

Em busca da teorização primeiramente o grupo executor participou de um treinamento e capacitação de batedores e manipuladores do fruto do açaí realizado pela vigilância sanitária do município de Belém em um local chamado "Casa do Açaí" localizado na Avenida João Paulo II, no bairro do Marco, município de Belém do Pará. A partir do conhecimento adquirido foi decidido levar até a população ribeirinha o processo de higienização de forma artesanal, prática e econômica por ser um município com alto índice de casos de 
Doença de Chagas por via oral. Os materiais utilizados foram adaptados pelas autoras em escala reduzida para demostrar o passo a passo de como higienizar adequadamente o fruto do açaí, entre eles estão: uma peneira; dois baldes, um sendo furado manualmente; quatro panelas; hipoclorito; e uma porção do fruto.

As tecnologias propostas foram adaptadas com a realidade da comunidade ribeirinha presente, sendo a primeira uma exposição de imagens que mostravam o vetor da doença, a forma de transmissão, a relação do vetor com açaí e os sinais e sintomas.

A segunda tecnologia consistiu na demonstração da higiene do fruto do açaí, sendo realizadas as etapas da higienização correta: o primeiro passo foi o peneiramento para eliminar a sujidade que acompanha o fruto; em seguida são executadas três lavagens, a primeira é realizada apenas com água para retirar a sujidade que ainda ficou após o peneiramento, a segunda o fruto deverá ficar de molho com hipoclorito durante 20 minutos e a terceira é feita com água potável para retirada do resíduo do cloro; posteriormente é feito o branqueamento que tem como objetivo reduzir a carga microbiana e inativação das enzimas oxidantes. Esta

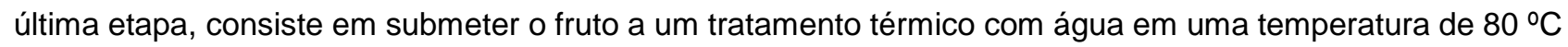
durante 10 segundos seguido por resfriamento com a água em temperatura ambiente; e por fim, o fruto estará pronto para o despolpamento que é o atrito do fruto com água potável, em máquina própria.

Ao final foi realizada uma dinâmica através de um jogo elaborado pelos autores que continham imagens e os nomes de cada processo de higienização embaralhados dentro de um envelope. A comunidade presente foi dividida em dois grupos, o objetivo do jogo era colocar os nomes das etapas em ordem e relacionar as imagens com cada etapa para testar os conhecimentos adquiridos durante a ação. Logo após, houve a distribuição de folders educacionais, com o intuito de informar o passo a passo da higienização do fruto.

Participaram da ação educativa 25 ribeirinhos do Rio Piramanha Alto II, dentre esses eram 4 homens e 21 mulheres, faixa etária prevalente de 19 a 68 anos. A maioria (88\%) apresenta baixo nível de escolaridade, tendo o ensino fundamental e o ensino médio, o que dificulta o entendimento da população para prevenção.

Percebeu-se que 24 (96\%) pessoas já ouviram falar da doença, porém, somente uma (4\%) pessoa soube explicar; 23 (92\%) pessoas não sabiam a relação da doença de chagas com açaí; 6 (12\%) pessoas apenas ouviram falar do processo de branqueamento, sendo que 25 (100\%) pessoas não sabiam as etapas do processo completo, e afirmaram fazer uso de açaí todos os dias; uma (4\%) pessoa relatou ter 5 pessoas na família com a doença de chagas na forma crônica.

Em relação os conhecimentos sobre como higienizar o fruto do açaí todos demonstraram não saber realizar o processo de forma adequada, o que pode gerar um grande risco de adquirir a doença. Ao final da etapa de repasse do conhecimento percebeu-se que os grupos participantes adquiriram conhecimentos suficientes para reproduzir com exatidão as etapas dos processos de descontaminação, limpeza e branqueamento do fruto.

Ocorreu uma dinâmica no final da ação voltada à avaliação de cada participante direcionada ao assunto abordado como método de comprovação do conhecimento, ao qual pode-se certificar se houve o entendimento efetivo e completo sobre a doença de chagas e o processo do branqueamento, gerando assim um saber na população presente para que este se perpetue e se dissemine na comunidade. O que demonstra a necessidade de ações educativas para população amazônica.

O desfecho da ação culminou com a solução de dúvidas que emergiram no decorrer e ao final das etapas, especialmente a respeito do vetor e como o branqueamento de fato garante o tratamento eficiente do açaí. As respostas satisfizeram o público e reforçaram a compreensão sobre o tema.

\section{DISCUSSÃO}

O estudo revelou que o conhecimento dos participantes da ação educativa referentes à doença de chagas relacionada ao açaí é diminuto, especialmente acerca das formas de execução correta das etapas de higienização do fruto. Segundo a Embrapa (2015), as adoções de boas práticas de manejo e fabricação 
minimizam a probabilidade de contaminação microbiológica dos frutos e do açaí durante o processamento, contribuindo para a conservação do produto

De acordo com o estudo de Carvalho RB, et al (2013) percebeu-se que o maior número de casos ocorreu em indivíduos com que a baixa escolaridade, evidenciando a vulnerabilidade social em que estão inseridos. Com isso, interfere na compreensão de questões socialmente relevantes como as formas de transmissão e profilaxia da doença.

Conforme Nogueira AKM, et al. (2013) o açaí é o principal alimento de grande parcela das famílias ribeirinhas e das famílias de baixa renda dos centros urbanos, o que causa um alto grau de dependência direta dos recursos naturais locais, tornando essa população mais suscetível a DC.

Especificamente no caso da Doença de Chagas, a rede de apoio familiar trouxe grande contribuição para a forma de como o cuidado foi buscado, já que a doença geralmente acomete mais sujeitos de uma mesma família, pois muitos são oriundos das áreas consideradas endêmicas (MARQUES AA e HENNINGTON ÉA, 2017).

Outrossim, Araújo RS, et al. (2015) ressalta que o protozoário T. cruzi, pode estar presente em fragmentos de barbeiros contaminados oriundos do peneiramento e lavagens ou por meio de dejetos de destes triatomíneos aderidas aos frutos, evidenciando a importância deste processo ao qual os frutos necessitam ser submersos em água a temperatura de $80^{\circ} \mathrm{C}$ durante dez segundos e, logo após resfriado em água potável a temperatura ambiente. Contudo, temperaturas superiores a $80^{\circ} \mathrm{C}$, ou períodos mais longos que 10 segundos, devem ser evitadas para não modificar as propriedades organolépticas do fruto.

De acordo com os achados de Ferreira RTB, et al. (2014) o açaí deve passar por diversos processos desde a coleta até o preparo para o consumo como peneiramento, lavagens, branqueamento e despolpamento, visando garantir um produto seguro. Silva MA, et al. (2014) reforça que o branqueamento, aplicado após a colheita, seleção e lavagem dos frutos, tem com objetivo inativar enzimas, fixar cor, remover gases dos tecidos, e diminuir a carga microbiana. De acordo com Santos FS, et al (2019), acredita-se que com pouca higienização dos alimentos, especificamente o fruto do açaí, a população consumidora fica com a maior probabilidade de transmissão ao ingerir o alimento contaminado. Os surtos de contaminações no Estado do Pará foram transmitidos particularmente pela via oral.

Contribuindo com a ideia Junior ASS (2017), a melhor maneira de prevenir o surto da doença em nossa região é apresentar maneiras eficientes de higienização na hora da colheita até a produção do fruto do açaí, conscientizar a população sobre a higiene na hora da compra da polpa do açaí. Corroborando para isso, a inovação tecnológica quando utilizada em favor da saúde auxilia, continuamente com a qualidade, eficiência, praticabilidade e garantia do cuidado, ou seja, quando usufruída de maneira apropriada que contribuem para um viver saudável entre os indivíduos que na sociedade são produtos e produtores. Assim, acredita-se que há espaço para a tecnologia e o cuidado ético/humanizado (SALVADOR PTCO, et al., 2011).

\section{CONSIDERAÇÕES FINAIS}

Ressalta-se a necessidade de estudos semelhantes a este para a melhor percepção a respeito da doença de chagas e dos processos de limpeza, descontaminação e branqueamento do açaí. Dessa forma, é notória o interesse de projetos de ação similares que visem à prevenção, estimulando a adesão de medidas simples de controle da doença. Observou-se que a falta de conhecimento sobre o assunto, o baixo índice socioeconômico e a baixa escolaridade associados a uma área considerada endêmica como fatores contribuintes para o aumento do índice da doença. A partir do uso de tecnologias educativas, se constrói uma ponte entre o educador e o educando, capaz de facilitar a entendimento e a aquisição de conhecimentos necessários para aperfeiçoar uma realidade e alcançar os benefícios que somente o processo educacional pode proporcionar, especialmente em populações vulneráveis, a exemplo, a capacidade de manipular o fruto do açaí de modo seguro e saudável ao consumo. Através da ação educativa houve uma significativa contribuição para que as pessoas adquirissem autonomia para identificar e utilizar as formas e os meios para preservar e melhorar a sua qualidade de vida. 


\section{REFERÊNCIAS}

1. AGUILERA ELR. Elaboração de um plano de ação para a prevenção da Doença de Chagas na comunidade Travessão, Município São Francisco-Minas Gerais. Trabalho de Conclusão de Curso (TCC) - Universidade Federal de Minas Gerais, Polo Montes Claros-Minas Gerais, 2015.

2. ALMICO JD, et al. Avaliação da qualidade microbiológica, físico-química e química de polpas de açaí (Euterpe oleracea Mart) pasteurizadas congeladas comercializadas em Aracaju-SE. Sergipe, 2018; 12:156-168.

3. ARAÚJO RS, et al. Doença de Chagas e Açaí: Avaliação do Conhecimento sobre a Patologia e Cuidados no Consumo da Fruta. 2015. In: IV CONGRESSO DE EDUCAÇÃO EM SAÚDE DA AMAZÔNIA. Belém: Pará. Disponível em: http://www.coesa.ufpa.br/arquivos/2015/expandidos. Acesso em: 14 abril 2019.

4. BARBOSA RL. Tratamentos de Aquecimento, Inativação Térmica e Virulência do Trypanosoma Cruzi (Chagas, 1909) de Vetores e Reservatório em Polpa in natura DE AÇAí (Euterpe oleraceae Martius) NA DOENÇA DE CHAGAS AGUDA DE TRANSMISSÃO ALIMENTAR NO ESTADO DO PARÁ, BRASIL. Dissertação (Doutorado em Parasitologia) - Universidade Estatual de Campinas, Campinas-SP, 2014; $311 \mathrm{p}$.

5. CARVALHO RB, et al. Perfil Biossocial Dos Indivíduos Portadores De Doença De Chagas Atendidos No Ambulatório De Infectologia Do Hospital Couto Maia, Salvador, Bahia. Salvador, 2013; 37: 133-143

6. COSTA MMR, et al. Doença de chagas: tendência epidemiológica por regiões do Brasil. Curitiba, 2018; 1: 252-259.

7. DIAS JCP, et al. II Consenso Brasileiro em Doença de Chagas. Brasília, 2016; 25: 7-86.

8. FALKENBERG MB, et al. Educação em saúde e educação na saúde: conceitos e implicações para a saúde coletiva. Rev. Ciência \& Saúde Coletiva, 2014; 19(3): 847-852.

9. FERREIRA RTB, et al. Transmissão oral da doença de Chagas pelo consumo de açaí: um desafio para a Vigilância Sanitária. Rev. Visa, em debate sociedade, ciência tecnologia, 2014; 2(4): 4-11.

10. GOMES EB, et al. Contribuição da Enfermagem para Prevenção da Doença de Chagas Transmitido por Açaí: Relato de Experiência. In: III CONGRESSO DE EDUCAÇÃO EM SAÚDE DA AMAZÔNIA. Belém: Pará. Disponível em: http://www.coesa.ufpa.br/arquivos/2014/expandidos/relatoexperiencia. Acesso em: 08 mar. 2019.

11. GRZEBIELUKA D. Por uma tipologia das comunidades tradicionais brasileiras. Revista Geografar Curitiba, 2012; 7(1): 116-137.

12. JÚNIOR ASS, et al. Análise espaço-temporal da doença de Chagas e seus fatores de risco ambientais e demográficos no município de Barcarena, Pará, Brasil. Rev. Bras Epidemiol, Belém-PA, v.20, n.4, p.742-755, 2017.

13. MARQUES AA, HENNINGTON ÉA. As repercussões da Doença de Chagas no contexto de vida e trabalho de usuários de instituto de pesquisa. Rio de Janeiro, 2017; 41:215-224.

14. NOGUEIRA AKM, SANTANA AC, GARCIA WS. A dinâmica do mercado de açaí fruto no Estado do Pará: de 1994 a 2009. Rev. Ceres, 2013; 60(3): 324-331.

15. OLIVEIRA FLB, et al. Extensão Universitária e as Ações Educativas para o Controle dos Vetores da Doença de Chagas em Santa Cruz- RN. Rev. Ciênc. Ext., 2017; 13(1): 128-136.

16. SANTANA AC, SANTANA AL, SANTANA ÁL. AÇAÍ PULP DEMAND IN THE RETAIL MARKET OF BELÉM, STATE OF PARÁ. Rev. Bras. Frutic., 2015; 39(1): 1-7.

17. SANTOS ÍFM. Transmissão oral da Doença de Chagas: breve revisão. Rev. de Ciências Médicas e Biológicas, 2014; 13 (2): 226-235.

18. SANTOS VRC, et al. Acute Chagas disease in the state of Pará, Amazon Region: is it increasing? Mem. Inst. Oswaldo Cruz, 2018; 113(5): 170-298.

19. SANTOS FS et al. Doença de chagas e sua transmissão pelo açaí: Uma revisão bibliográfica. Rev. Braz J. Hea, $2019 ; 2(2): 6$.

20. SILVA MA, et al. Polpa de açaí: o caso da produção do pequeno produtor urbano de Manaus. Scientia Amazonia, 2014; 3: 65-71.

21. SILVEIRA RSO, et al. Construção de Tecnologia Educativa para Incentivar Puérperas ao Aleitamento Materno. Ceará, 2016; 1: 1-3.

22. VARGAS A, et al. Investigação de surto de doença de Chagas aguda na região extra-amazônica, Rio Grande do Norte, Brasil, 2016; 34: 1-8. 